21.1

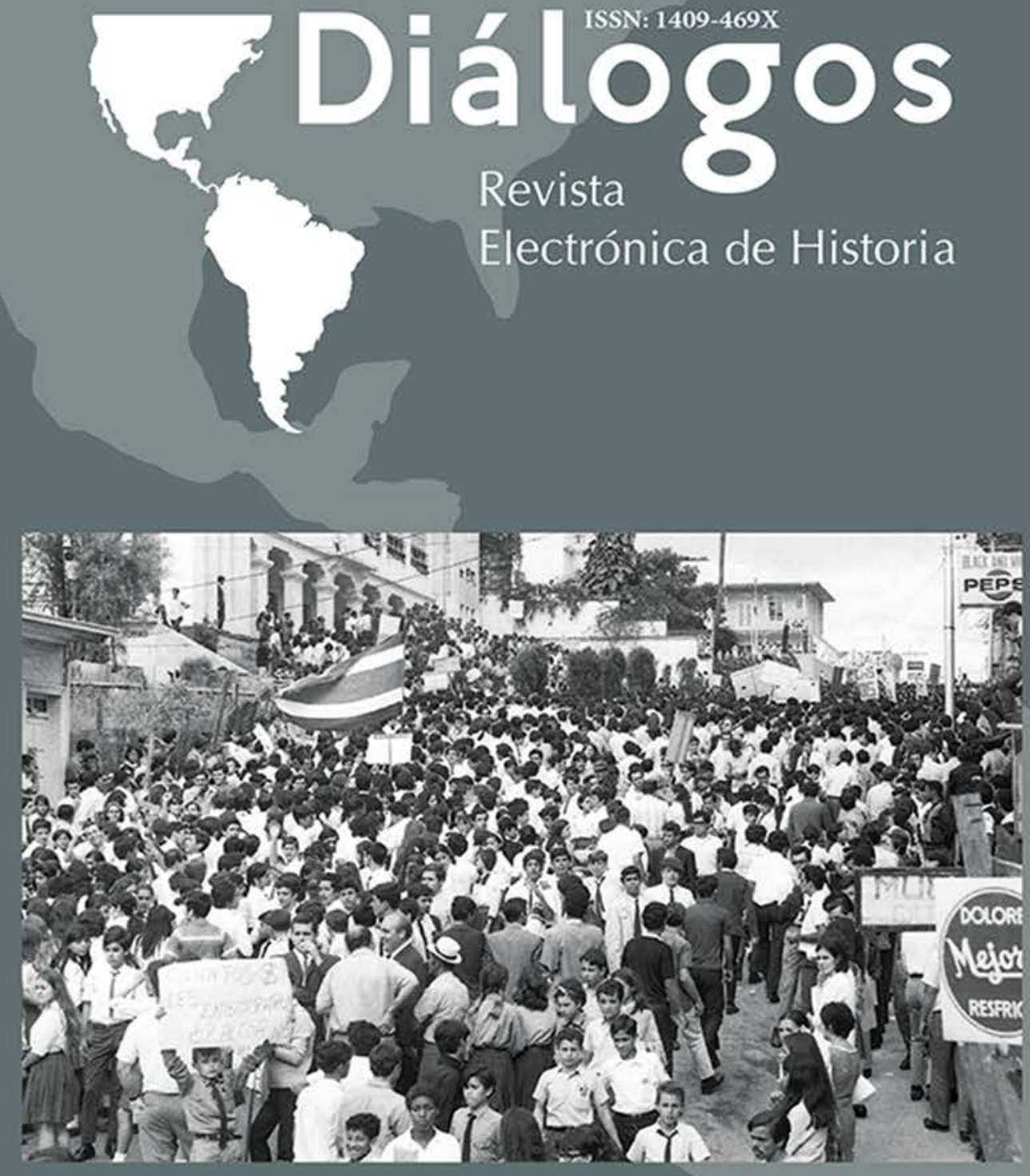

Centro de Investigaciones Históricas de América Central. Universidad de Costa Rica

\title{
Enero-junio 2020
}

url: http://revistas.ucr.ac.cr/index.php/dialogos/index

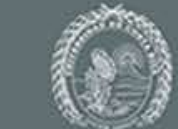

UNIVERSIDADDE

COSTARICA

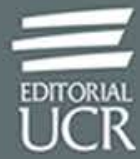




\title{
REFLEXIONES SOBRE EL CARÁCTER SITUADO DE LA CIENCIA: SUS APORTES PARA UNA HISTORIA DE LA MICROBIOLOGÍA EN AMÉRICA LATINA
}

Gabriel Augusto Matharan

\begin{abstract}
Resumen
El presente trabajo tiene como objetivo presentar una primera problematización de tres temas que la historiografía de la ciencia contemporánea considera centrales para analizar, a partir del reconocimiento, el carácter situado de la actividad científica y de cómo las mismas pueden enriquecer una historia de la microbiología en América Latina. Con tal fin se abordan los aspectos temporales, espaciales y de género de la ciencia. El trabajo muestra que entender la microbiología de manera situada en Latinoamérica requiere hacer visible una multiplicidad y heterogeneidad de espacios, tiempos y marcas de género en sus mutuas articulaciones.

Palabras clave: microbiología, América Latina, ciencia, historia situada, dimensiones temporales, espaciales y de género, investigación científica, historia social, espacio y tiempo (historia), historiografía, estudios.
\end{abstract}

\section{REFLECTIONS ON THE SITUATED NATURE OF SCIENCE: CONTRIBUTIONS TO A HISTORY OF MICROBIOLOGY IN LATIN AMERICA}

\begin{abstract}
This study aims to present an initial problematization of three dimensions, from the historiography of contemporary science, considered fundamental in order to analyse and recognize the situated character of scientific activity. Moreover, it pretends to portray how these dimensions enrich the history of microbiology in Latin America. Thus, the temporal, spatial, and gendered aspects of science are addressed. This study shows that understanding microbiology from a situated perspective in Latin America requires the acknowledgement of a multiplicity and heterogeneity of spaces, times, and gendered dimensions in all their mutual articulations.
\end{abstract}

Keywords: microbiology, Latin America, science, situated history, temporal, spatial, and gendered dimensions, scientific research, social history, space and time (history), historiography, studies. 


\section{INTRODUCCIÓN ${ }^{1}$}

El trabajo del historiador a secas debe repartirse entre dos exigencias (Chartier, 1996). La primera, clásica y esencial, consiste en proponer la interpretación/explicación más adecuada posible de un objeto o un problema en un territorio de indagación particular que define su competencia. La segunda es la de reflexionar sobre el proceso de producción de conocimiento a partir de una indagación acerca de las condiciones sociohistóricas de posibilidad de los problemas, conceptos y teorías que se movilizan junto a los desafíos que presentan.

En el marco de esta última exigencia, el presente trabajo tiene como objetivo presentar un análisis de algunas de las dimensiones involucradas en el reconocimiento, por parte de la historiografía de la ciencia contemporánea, del carácter situado/contextual de la actividad científica (Shapin, 1998; 2000). Es relevante remarcar que estas son cuestiones que habría que documentar para futuras investigaciones y que en este trabajo se pretende realizar una primera tematización.

Reconocer el carácter situado consistió en restituir la ciencia a su contexto social, cognitivo, espacial y temporal en sus ricas interrelaciones. Con tal fin, se establecieron algunas hipótesis entre los contextos de emergencia de las prácticas científicas, las relaciones internas en el ámbito de producción de conocimientos, los contenidos de esos conocimientos y sus viajes/movilidad ${ }^{2}$ hacia otros contextos. Una posición representativa de esta postura es la del historiador de la ciencia Steven Shapin quién, en 1996, sostuvo que "doy por supuesto que la ciencia es una actividad social históricamente situada, que debe ser entendida en relación con los contextos en los que se desarrolla" (Shapin, 2000, p. 26). ${ }^{3}$ Con posterioridad desarrolló más esta afirmación, sosteniendo que la ciencia es producida por personas con cuerpos, situadas en un tiempo, espacio, cultura y sociedad que luchan por la autoridad y credibilidad científica (Shapin, 2010).

Esta consideración situada promovida por el enfoque que, genéricamente podemos denominar constructivista (Shinn, 1999), puso en discusión el supuesto carácter universal y neutral de la actividad científica: la creencia de que la ciencia constituye una esfera autónoma de operaciones intelectuales ${ }^{4}$ y el pretendido carácter privilegiado y fundamentado del conocimiento científico para acceder al mundo natural y social. Para la región latinoamericana, esto permitió poner en tela de juicio una historiografía de la ciencia que por mucho tiempo sostuvo o bien que el desarrollo de la ciencia en esta región fue inexistente o "que había recorrido, por imitación, las mismas etapas que el desarrollo científico de los países industrializados en Europa" (Cueto, 1996,p. 481). Esto armó una agenda de investigación de la historia de los desarrollos científicos (truncos y exitosos) en América Latina (AL) a partir de la reconstrucción de las formas en que se encontraban ligadas a las condiciones y tradiciones culturales e intelectuales locales.

Tributarios para este enfoque es el título del presente trabajo, que sitúa una historia de la microbiología en una región particular: AL. ${ }^{5}$ El desarrollo del mismo adoptará la siguiente organización: en primer lugar, abordaremos tres de los aspectos involucrados en la producción del conocimiento científico según Shapin (Shapin, 2010): 
los agentes involucrados (haciendo hincapié en la cuestión de género), el tiempo y el espacio. A modo de cierre, reflexionaremos sobre cómo puede enriquecer esta perspectiva de estudio para quien encaré un estudio histórico de la microbiología en América Latina, al margen de cuál sea su campo o el período específico del que se ocupe.

\section{LA DIMENSIÓN TEMPORAL DEL CARÁCTER SITUADO}

Una dimensión central a la hora de considerar el carácter situado es haciendo foco en el aspecto temporal. Muchas disciplinas sociales, humanas, naturales e ingenieriles tienen una larga historia de tratamiento del concepto del tiempo. También para la historiografía, este es uno de los conceptos fundamentales indagados, a la vez que se considera categoría fundamental ontológica para la comprensión de la historia. Así, el reconocido historiador francés Le Goff sostuvo que "la historia es ciencia del tiempo" (Le Goff, 1997, p. 53). En cuanto tal, la historia moviliza diferentes conceptos como los de duración, tiempos vividos, tiempos múltiples y relativos, historicidad/regímenes de historicidad, tiempos subjetivos y simbólicos, entre otros, para captar la naturaleza del tiempo.

Con mayor precisión, Chartier afirma que "la especificidad de la historia, dentro de las ciencias humanas y sociales, es su capacidad de distinguir y articular los diferentes tiempos que se hallan superpuestos en cada momento histórico" (Chartier, 2007, p. 88). Recordemos que fue el historiador Fernand Braudel (Braudel, 2002) quien, en 1947, presentó la primera formulación de la descomposición del tiempo de la historia en un tiempo largo vinculado a la geografía, medio relacionado con lo social y corto unido a lo individual, acontecimental y político. Además, planteó la idea de un historia casi inmóvil, de lento fluir y transformación. En 1958, este introdujo una modificación a esta primera formulación al sostener que cualquier dimensión del pasado (económica, política o geográfica) podía estar articulada a un tiempo largo o corto (Braudel, 2002a). Aquí el concepto de larga duración aparece más teorizado y formalizado.

En el año 2000, el historiador y filósofo alemán Reinhart Koselleck reconocía la fertilidad de pensar el tiempo compuesto en diferentes estratos, ya que permitía "tematizar las distintas velocidades del cambio sin caer en la alternativa entre cursos temporales lineales o ficticios" (Koselleck, 2001, p. 42). Siete años más tarde el historiador francés Roger Chartier también reclamó la necesidad, para el campo de la historia y de las ciencias sociales en general, de repensar y teorizar la arquitectura braudeliana de las duraciones encastradas (larga duración, coyuntura, acontecimiento). En tal sentido, avanzó sosteniendo que las variedades de las temporalidades no son exteriores a las relaciones sociales de una determinada sociedad, sino que hay que entenderlas como unas propiedades sociales (distribuidas muy desigualmente) articuladas con las condiciones sociales y económicas. En cuanto tal, "son producciones sociales que aseguran el poder de unos (sobre el presente o el futuro, sobre sí mismos o sobre los demás)" (Chartier, 2007, p. 93) 
Con este reclamo en mente cabe, al menos, formularse dos preguntas para la historia de la ciencia. La primera de ellas es si esto sería posible y la segunda, cómo podría traducirse la propuesta de los estratos del tiempo de Braudel. Para ello, habría que ponderar qué tipos de temporalidades se encuentran involucradas en la ciencia en AL y, de manera diferenciada, en cada uno de los países que la conforman. Temporalidades asociadas, por ejemplo, a la obtención de una titulación científica, la formación para la investigación, el abordaje de un problema, los proyectos de investigación, las carreras científicas, la escritura y publicación de papers, la participación en congresos, las evaluaciones a que se ven sometidos los investigadores y las investigadoras, la producción de conocimiento y los cambios cognitivos, entre otros. Aquí hay que remarcar la necesidad de incluir las diferencias de género en el análisis. ${ }^{6}$

En la historiografía de la ciencia hay antecedentes, estimulantes y ricos, para comenzar a pensar en estas temporalidades. En efecto, la noción de régimen de saber (Pestre, 2005) busca captar una manera de "ser y estar" de la ciencia y la investigación en un tiempo largo y de cambio lento. ${ }^{7}$ Pestre (2005) sostiene la existencia de tres regímenes de saber: desde el siglo XVI al siglo XIX, desde 1870 a 1970 y desde 1970 y en curso todavía. También la noción de régimen epistémico propuesto por Oscar Vallejos busca capturar en una temporalidad de mediano y largo plazo el modo de existencia social de la ciencia y la tecnología (Vallejos, 2010). Además, propone el concepto de proyecto cognitivo para hacer visible "el armado de un plan de acción que organiza el trabajo cognitivo o intelectual en función de metas de largo plazo en función de los recursos con los que cuenta el agente (investigador)" (Vallejos, 2012, p. 11). ${ }^{8}$

La segunda de las preguntas se refiere a cómo se articularían los tiempos de la sociedad y los tiempos de la ciencia. Una forma de responder es por medio del reconocimiento de que la sociedad está formada por instituciones y agentes (individuales o colectivos) que trazan planes sobre la existencia de la ciencia con diferentes urgencias y ritmos. En este marco Nowotny (2011) señala, por ejemplo, la tensión existente entre los tiempos de la producción del conocimiento científico, que implican un tiempo largo, y los tiempos de los políticos y políticas (esfera de la política) que demandan y requieren una solución por parte de la ciencia en el corto plazo, ya que se encuentran sometidos a la presión de los ciclos electorales. Esta línea de razonamiento refuerza el cuestionamiento hacia los trabajos que toman casi exclusivamente elementos de la historia social o política para construir una periodización determinada. Frente a este planteo, diversos autores al estudiar los casos de la biología molecular (Kreimer, 2010) y la investigación en catálisis (Matharan, 2011) han sostenido que la dinámica de la ciencia no puede ser explicada en función de lo político, a pesar de que en ocasiones puede coincidir con la dinámica de la política convencional, sino que hace falta ponderar las dimensiones sociocognitivas de esta disciplina junto a su relación con la dinámica internacional. 


\section{LA DIMENSIÓN ESPACIAL DEL CARÁCTER SITUADO}

El segundo de los aspectos abordados será el espacial. Para su estudio, se dividirá en los siguientes ejes: a) los lugares y escalas de observación; b) la tensión entre lo nacional y lo global (Harvey, 2007); y c) la geopolítica de la producción científica.

\section{Los lugares y las escalas de observación}

¿Cuáles son las formas y las dinámicas espaciales de ordenamiento de la ciencia y la investigación? Esta pregunta nos plantea, en el desarrollo histórico, el problema de la diferenciación y la atribución de significación estratégica y articulación (integración) de los diferentes niveles involucrados que dan forma a la práctica científica, tanto constriñéndola como posibilitándola. Un primer nivel refiere a aquellos aspectos de las condiciones espaciales delimitadas por la naturaleza en la que se enmarca el desarrollo de una sociedad: geológicas, geográficas, zoológicas, vegetales y astronómicas. Un segundo nivel contempla los aspectos generales de la sociedad (cultura, economía, política) que son responsables de las actitudes hacia la ciencia y se expresan en un estilo particular (Saldaña, 1996). Un tercer nivel identifica los diferentes ámbitos institucionales (estatales y no estatales) con sus respectivas necesidades, intereses, culturas y normas ${ }^{9}$. Un cuarto nivel desglosa las variadas formas espaciales sociocognitivas que operan en diferentes planos: campos, disciplinas, especialidades, áreas de investigación, escuelas de investigación, laboratorios (Prego, 1996). Por último, en un quinto nivel se hacen visibles los "lugares", pequeños o grandes, donde tiene lugar la producción o movilización del conocimiento. Entre ellos podemos nombrar los laboratorios, un café, así como también a las ciudades, una provincia y un país.

Siguiendo a Koselleck se podría hacer una clasificación de estos niveles. En un extremo, se encuentran aquellos espacios que una sociedad no crea, por ejemplo, sus condiciones geográficas, y en el otro extremo, aquellos espacios que una sociedad crea o se ve obligada a crear para poder desarrollarse. Entre ambos extremos emerge una situación de tensión productiva (Koselleck, 2001a) difícil de distinguir entre lo natural y lo social, dando lugar a los espacios híbridos o coproducidos (Nowotny, 2011). Paradigmático de ello es el cambio climático: un fenómeno natural causado en gran medida por la intervención social en el entorno natural y viceversa, lo societal en su conformación se ve cada vez más influenciado por los fenómenos naturales (aumento de los regímenes de lluvias, huracanes, terremotos, etc) vinculados al mencionado cambio. En consecuencia, las escalas espaciales y temporales de la naturaleza y de la sociedad se ajustan y coinciden cada vez más.

La identificación de estos niveles/escalas nos interroga, a su vez, por el problema de la mirada que ha dado lugar a dos modalidades de la historia de la ciencia, a nuestro entender complementarias. Nos referimos a una macrohistoria y a una microhistoria de la ciencia. La idea de una distinción entre lo micro y lo macro 
no refiere a la idea de la dimensión de objeto de análisis, sino a la dimensión de la "realidad observada" (Revel, 2005). Como sostiene Jacques Revel (2005), lo importante de la variación de la escala, que puede usarse con fines experimentales, es que nos revelará factores antes no observados a la vez que modifica su trama y forma.

Una posición más radicalizada que discute esta diferenciación es la sostenida por Bruno Latour en su clásico artículo de 1983 "Dadme un laboratorio y moveré el mundo", en donde cuestiona la creencia en una supuesta diferencia real de escala entre objetos macros y micros de una sociedad. En tal sentido, con su estudio mostraba la dificultad para hacer dicha distinción preguntándose dónde está el laboratorio y dónde está la sociedad (Latour, 1995, p. 246). Latour promovió entonces anular o abandonar las dicotomías de escalas por considerarlas falsas. De hecho, para él la sociedad no existe, lo que existe son redes heterogéneas e híbridas entre actores humanos y no humanos. ${ }^{10}$

En la misma línea del planteo de Latour, Shapin, representante en la historia de la ciencia del Programa Fuerte de Edimburgo, afirmó también que "hay tanta "sociedad" en el laboratorio científico y en el desarrollo del conocimiento científico, como "fuera" y que la distinción entre lo "social" y lo "político", por un lado, y la "verdad científica", por el otro, es parte de un producto cultural del período XVI y XVIII (Shapin, 2000).

Más allá de estas controversias, durante el siglo XIX predominó una historia de la ciencia que recortaba sus objetos de estudio en la escala de lo nacional, pero hacia finales del siglo XX en la historiografía y en las ciencias sociales, fue postulándose la idea de una escala macro o global. Esto produjo una discusión sobre la relación entre lo nacional y lo global.

\section{Nación y globalidad}

El reconocido médico, investigador y premio Nobel argentino de fisiología, Bernardo Houssay, afirmó que la ciencia no conocía de nacionalidad, pero que el investigador e investigadora sí. Sin embargo, admitiendo el carácter situado y local de la ciencia, sería posible afirmar que tanto el investigador como la ciencia tendrían nacionalidad. Con ello se abre el problema del proceso de nacionalización, que pude ser entendido al menos de tres maneras: por un lado, significa el surgimiento de un estilo nacional de hacer ciencia (Bensaude-Vincent \& Stengers, 1997; Vessuri,1995); por el otro, el surgimiento de tradiciones científicas nacionales modernas en el contexto de las nuevas naciones poscoloniales (Vessuri, 1996); por último, está asociado a la emergencia de un sentimiento de pertenencia a una comunidad científica con una determinada frontera e identidad nacional que estructura y delimita el territorio de la ciencia y de los que a ellos se dedican (Hufbauer,1982; Bertomeu Sánchez \& García Belmar, 2006).

En este último, sentido habría que indagar en la constitución de un colectivo de científicos y científicas, una comunidad a la vez real como imaginada (Anderson, 1993) 
con una identidad propia, definida por la doble condición de compartir una dedicación común a la microbiología y por pertenecer a un mismo contexto geográfico, territorial y simbólico. ${ }^{11}$ Con esta doble identidad, surgieron espacios o "esferas" de intervención e interlocución diferenciados, pero profundamente imbricados, es decir, mientras que en la comunidad científica se discute la ciencia, en la nación se discutía las condiciones de posibilidad para hacer ciencia a la vez que se orientaba, al menos retóricamente, la ciencia hacia los problemas de esta.

En tensión con la nacionalidad de ciencia, se encuentra la denominada historia global ("global history") de la ciencia, uno de los temas que se ha vuelto principal en las últimas décadas en la historiografía actual. La emergencia de esta historia hunde sus raíces en la necesidad de considerar los logros intelectuales de las culturas no occidentales, a la vez que en una serie de rechazos: rechazo del marco del Estado-nación que delimita, retrospectivamente, una entidad social y cultural ya presente incluso antes de su advenimiento político; rechazo de los recortes tradicionales de los trabajos históricos que exploran las especificidades de una provincia, una región o una ciudad; y por último, rechazo del enfoque microhistórico por haber descuidado lo "lejano" y lo macro.

La historia global de la ciencia, sin embargo, plantea el problema de definición: ¿qué se entiende por ella? La respuesta implica responder otras preguntas: ¿constituye una forma nueva de comparación?, ¿supone la identificación de diferentes espacios transnacionales que hallan su unidad histórica en las redes de relaciones y de intercambios que los constituyen, al margen o más allá de las soberanías estatales?, ¿es una historia de los contactos, encuentros, las aculturaciones y mestizajes? (Chartier, 2007), o ¿es una historia que se aboca al estudio del impacto de la Globalización en sus diferentes etapas con una dimensión planetaria? (Viales, 2018).

Todas estas interrogantes, sea cual fueran sus respuestas y que suponen una historia a muy gran escala, plantean un desafío importante a las prácticas de los historiadores y las historiadoras: el seguimiento y el análisis de fuentes presentes en diversos países, el dominio de las lenguas en las que están escritas y el conocimiento exhaustivo de los diferentes contextos que conforman a la vez que son conformados por las prácticas científicas.

Otro de los problemas es justamente el de la especialidad: como se modifican los espacios nacionales científicos en este espacio global. Con ello las dinámicas temporales, los mecanismos de conformación y las modalidades de interconexión en este espacio de la práctica científica global se vuelven centrales.

\section{Geopolítica del conocimiento}

El énfasis puesto en los lugares donde se produce el conocimiento científico dio lugar a un campo preocupado por la articulación entre el poder y las geografías del conocimiento. Como señala Hebe Vessuri, en la práctica se observa que la comunidad científica internacional es altamente estratificada, no sólo en función 
del criterio de mérito, sino también de una combinación de mérito y situación socio-institucional-espacial que permite hablar de una socioeconomía política de la ciencia (Vessuri, 1991). Además, como bien señala Koselleck, la geopolítica, desde el punto de vista de la historia de la ciencia, surgió en el horizonte de reconocer el carácter interdependiente e interconectado de todas las acciones económicas, políticas y científicas (2001a).

Esa estratificación e interdependencia produce una división social internacional del trabajo científico con un consecuente desbalance en la producción y en los intercambios de conocimientos, dando lugar a centros y periferias. ${ }^{12}$ Esta división social del trabajo científico impondría a las periferias un trabajo basado en actividades de alto contenido y especialización técnica subsidiaria de agendas de investigación, conceptos, teorías y las innovaciones institucionales definidos previamente en el centro. Si bien las actividades llevadas a cabo en la periferia son importantes para el desarrollo global del problema, no implican per se avances significativos en términos conceptuales (Kreimer, 2010).

Las relaciones centro-periferia también pueden ser mentales (simbólicas), existiendo formas de percepción que implican el reconocimiento de la condición periférica por los propios científicos locales, quienes llegan a expresar esto en forma de sentimientos ligados a vivencias personales dolorosas (Vessuri, 1991; Ledesma, 2009).

Es importante cuestionar la absolutización de esta estratificación o desigualdad de poder, adoptando una perspectiva que las considere como resultado de una dinámica histórica, relacional construida y reproducida social y cognitivamente. Hay que estudiar los modos en que estas relaciones de poder se alimentan, se sostienen y se representan buscando indagar en una causalidad exo-generada como también en causalidades endo-generadas de la dinámica local (Dagnino y Thomas, 2000). Así se puede encontrar centros y periferias que, dependiendo de los temas de investigación, pueden ser a la vez centros y periferias; centros que pueden convertirse, con el tiempo, en periferias y viceversa, y puede haber países que sean centros y periferias a la vez (Gavroglu et al., 2008).

Por otro lado, también es relevante señalar que las relaciones de poder asimétricas no son absolutas, ya que esto anularía toda la capacidad de autodeterminación intelectual a los países dominados como así también las resistencias y las insumisiones. Si fuera así, se negaría la posibilidad de hablar de la existencia misma de "campos" fuera de las académicas centrales. Su rol activo queda al menos plasmado en los procesos de integración que, más allá de la subordinación o dependencia (académica) respecto de los centros, implican procesos de apropiación y de resistencia frente a la imposición, explícita o implícita, de modalidades de prácticas científicas. Por ello, son importantes las modalidades mediante las cuales se establecen las relaciones de poder, los márgenes para las negociaciones, como también analizar las estrategias de resistencias. Por ejemplo, una estrategia de resistencia podría ser analizar los mecanismos de apropiación-transformación de los temas/problemas y conocimientos y/o recursos financieros para utilizarlos en otras investigaciones 
de interés personal o nacionalista (asociación ideológica entre ciencia y desarrollo) (Vessuri, 1984). Fernanda Beigel analizó, por su parte, cómo las ciencias sociales latinoamericanas desarrollaron estrategias para superar la dependencia académica, alcanzando en la década de 1960 un alto nivel de desarrollo institucional y de autonomía intelectual. Se generó, para ello, un vigoroso circuito subregional alternativo de circulación del conocimiento y se consolidaron sistemas universitarios públicos de gran tamaño en Brasil, México, Argentina y Chile, surgiendo tradiciones académicas de investigación locales que adquirieron cada vez más fuerza. Esto le permite suponer que "no hay "exportador" puro de teorías y un "importador" pasivo de las mismas, "ya que los intercambios simbólicos, por más desiguales que sean, no son unilaterales" (Beigel, 2010, p. 22). ${ }^{1}$

Esta última condición no invalida que la consideración del desarrollo de la ciencia en los contextos no europeos, como AL, no pueda enriquecer los análisis sobre este proceso a nivel internacional y a la vez pensar en qué medida esos desarrollos contribuyen en la actualidad, al igual que en el siglo XIX, a lo que sucede en los países centrales o cómo han surgido "centros periféricos" que tuvieron un rol especialmente en la región.

\section{El espacio como un agente}

Una manera muy original de considerar el espacio fue el realizado por Fernand Braudel en la renombrada obra histórica "El Mediterráneo y el mundo mediterráneo en la época de Felipe II" de 1947. Aquí el autor sitúa el espacio mediterráneo como un personaje que actúa, que tiene voluntad y que tiene una historia propia, en definitiva, como una fuerza creativa de la historia europea. En efecto, afirma que "concentrándose en un personaje fuera de serie, aprovechar su masa, sus exigencias, sus resistencias y sus trampas, aprovechar también su impulso, para intentar construir una historia distinta de cómo nuestros maestros la enseñaban" (Braudel, 2002). En el plano de una historia muy grande y casi inmóvil, casi fuera del tiempo, el trabajo se centraba en la relación de los hombres con (y sobre) un espacio líquido y viceversa. En definitiva, era un trabajo de lo que él denominaba como geohistoria. ${ }^{14}$

Recientemente en la historia de la ciencia, se ha retomado la indagación de otro espacio líquido: el espacio natural-social transatlántico. Ahora, el océano atlántico se conforma como una fuerza creativa y de unión de la historia, ya no solo de Europa sino de también de América Latina en sus mutuas influencias e interacciones. En este sentido, la unidad del Atlántico es la de un viaje de retorno, de movilidad y de circulación.

Para desarrollar más esta manera de considerar al espacio, puede resultar estimulante, al menos en términos heurísticos, considerar el enfoque teórico de Ciencia, Tecnología y Sociedad de Michel Callon y Bruno Latour, que adopta la premisa metodológica y, quizás como una verdad ontológica, de que el mundo moderno se compone de redes-actores donde los actores sociales significativos incluyen humanos y no humanos (actantes). 
Recordemos que esta teoría atribuye voluntad, objetivos y estrategias a entidades físicas (electrones, por ejemplo) y biológicas (las vieiras, por ejemplo) no humanas. Entidades que moldean nuestras acciones, permitiéndolas o restringiéndolas, limitándolas, condicionándolas. De acuerdo con esta tesis sociológica, en las controversias científicas, los investigadores e investigadoras "reclutan" y "negocian" con los actantes, traduciendo sus intereses para movilizarlos y ubicarlos de su lado.

Para la historia de la ciencia, dos conceptos de esta teoría son importantes: ensamblar y co-producir. La historia de la ciencia consistiría, entonces, en estudiar los procesos de ensamblaje de elementos heterogéneos (humanos y no humanos) que intervienen en la construcción, definición, controversias y solución de los problemas cognitivos (Jasanoff, 2013), como también en estudiar los procesos de co-producción de los mundos sociales y naturaleza entre la ciencia, sociedad y naturaleza en sus interdependencias mutuas y complejas (Jasanoff, 2013, 2011, 2004; Nowotny, 2011). ${ }^{15}$

\section{LA DIMENSIÓN DE GÉNERO DEL CARÁCTER SITUADO}

El último aspecto que aquí abordaremos a la hora de considerar el carácter situado es cómo una determinada sociedad organiza de manera diferente el vínculo con la ciencia en función de las marcas de género. Esta cuestión suele identificarse con las relaciones entre las mujeres y la ciencia. ${ }^{16}$

Desde hace algunas décadas, los historiadores e historiadoras se ocupan de la "historia desde abajo" como inversión y cuestionamiento de la "historia desde arriba". Estas historias pueden adquirir diferentes significados. Así, la historia desde abajo podría pensarse como la historia de los vencidos, los excluidos, los silenciados versus la historia de los ganadores, incluidos, con voz, aquellos que han escrito y escriben la historia (Burke, 2003, pp. 17-18). También la historia desde abajo podría pensarse como la historia de los pobres, sin educación y de aquellos que tienen una educación diferente a la cultura letrada o, de manera más general, de la gente corriente y común versus la historia de la cultura letrada, en definitiva, de la historia desde el y para el poder.

Pero no deberíamos suponer, desde luego, que todos los agentes corrientes tienen la misma experiencia, de ahí la importancia de reivindicar la historia de las mujeres cuestionando la posición historiográfica dominante de la historia y sus agentes humanos universales establecidos, es decir, los varones blancos como ha subrayado la historiadora Joan Scott (2003). Frente a esta situación, la historia de las mujeres se enfrenta inevitablemente al "dilema de la diferencia" (Scott, 2003, p. 70).

En el campo CTS, la investigadora Donnay Haraway (1988) escribió un famoso ensayo sobre el conocimiento situado en el cual hace hincapié en la dimensión de género. También Pérez Serdeño sostuvo que "el análisis de las relaciones entre la ciencia y el género ha proporcionado argumentos y casos de estudio para el debate general acerca del papel de los valores no cognitivos o contextuales en ciencia..." (Pérez Serdeño, 2001, p. 25). Entre estos factores tradicionalmente considerados 
como "extracientíficos" que condicionan la génesis y la validación científica, se ubica el género. En efecto, en el análisis de la manera en que la ciencia se relaciona con la sociedad, las relaciones entre ciencia y género son relevantes. El carácter situado de la ciencia se revela en los valores de género que guían las investigaciones, determinan qué hipótesis seleccionar y qué métodos de contrastación se van a utilizar (Pérez Serdeño, 2001).

En consecuencia, una perspectiva feminista de la historia de la ciencia nos enfrenta a las siguientes dimensiones de indagación: a) el lugar/participación de las mujeres que actuaron en los márgenes y fueron olvidadas en y por la historia de la ciencia; b) las barreras y mecanismos de exclusión como también las resistencias ofrecidas y las conquistas obtenidas de las mujeres; c) las jerarquías sexuales (o el sesgo de género) y las condiciones, desarrollo, difusión, uso y contenido de la ciencia; d) la retroalimentación entre la ideología de género y la de la ciencia en su construcción mutua (Fox Keller,1991); e) la construcción de la mujer por parte de la ciencia; f) las ciencias y la producción de conocimientos sobre el género y la constitución de subjetividades; g) los conocimientos que eran portados por las mujeres y le fueron ocultados, arrebatos u olvidados por parte de los varones; y por último, h) la construcción de género del espacio y tiempo.

Toda historia que tenga la pretensión de contar la totalidad de lo sucedido en el pasado, no puede entonces dejar a las excluidas. En definitiva, como señala Sánchez Ron, una historia de la ciencia centrada en la dimensión social no puede dejar de lado el tema de la mujer y su marginación de la profesión científica (1992). Este problema ha adquirido creciente interés e intensidad durante el siglo XX y, sin embargo, sigue siendo muy resistido. En la historiografía de las ciencias en Argentina, por ejemplo, "la cuestión de género no ha constituido un campo de indagación particular y son poco frecuentes los trabajos que se detienen en la situación (exclusión) de la mujer en la actividad científica local" (García, 2006, p. 137).

\section{CONCLUSIONES: ¿QUÉ PODEMOS APRENDER DE ESTOS MÚLTIPLES ASPECTOS PARA UNA HISTORIA DE MICROBIOLOGÍA EN AL?}

La historia de la microbiología en AL, todavía escasa y recortada por los espacios nacionales, se ha centrado fundamentalmente en el estudio del ingreso y la institucionalización de la bacteriología en el campo de la medicina (de manera más general podemos hablar del campo biomédico). Así contamos contrabajos sobre el surgimiento de las primeras cátedras de bacteriología, sus promotores y primeros profesores, las dimensiones internacionales involucradas, los institutos bacteriológicos nacionales y las articulaciones entre enfermedades tropicales (paludismo, fiebre amarilla) y la investigación bacteriológica/médica. ${ }^{17}$ En estos trabajos, muchas veces no se hace una distinción entre la bacteriología y la microbiología, 
usándose indistintamente ambos términos. Se plantea esto ya que en Argentina, por ejemplo, si bien surgen cátedras de bacteriología en las carreras de medicina, también se constata la creación de cátedras específicas de microbiología en ámbitos como la química, la biología, la bioquímica y de diversas ingenierías como la química, en alimentos, ambiental e industrial. Se puede apreciar, de esta manera, la conformación de identidades diferenciadas entre la bacteriología y la microbiología, según las disciplinas y profesiones. Esto que sucede en Argentina necesita ser investigado en el resto de los países latinoamericanos.

En este contexto cabe preguntarse, de manera general, cómo y cuándo la microbiología adquirió una identidad propia, tanto disciplinar como profesional, ${ }^{18}$ y si es posible hablar de una microbiología latinoamericana. Y viceversa, en qué medida la investigación microbiológica ha contribuido (y contribuye) a la formación de una región latinoamericana. Dicho esto, habría que desagregar esta región, a su vez, en diferentes espacialidades socio-naturales desde las condiciones naturales pasando por las ciudades, países, subregiones, instituciones, redes, comunidades, hasta las subdisciplinas que la conforman, las posibles escuelas de investigación, las áreas de investigación, etc. Sin embargo, también hay que investigar cómo la microbiología posee o involucra un conocimiento geográfico en su propio conocimiento al elaborar, por ejemplo, un mapa o territorio de una enfermedad.

El carácter situado de la microbiología sería una manera de pensar o de entender el modo en que se relaciona con y en un espacio-tiempo, como es AL, atendiendo a las relaciones de poder/dominación intra y extra regional. Aquí se sostiene que tanto el espacio social y natural como el tiempo pertenecen a las condiciones de posibilidad de una historia de la microbiología, pero tanto el espacio como el tiempo tienen una historia en la medida en que son modificados por capacidad de agencia humana distribuida desigualmente entre varones y mujeres en contextos sociales, culturales, económicos y científicos particulares. Cabe estudiar, entonces, cómo se expresan históricamente y de manera distintiva en la microbiología.

Por otro lado, cada uno de estos espacios, a su vez, lleva o implican un tiempo en su dinámica de cambios y permanencias. Cabe indagar en sus temporalidades largas, medias y cortas, así como las estratificaciones temporales construidas y distribuidas socialmente (desigualmente). También hay que estudiar las temporalidades en los contextos periféricos. Recordemos que el concepto mismo de periferia no sólo refiere a la cuestión espacial sino también temporal. En efecto, las periferias aparecen como retrasados respectos a los centros más adelantados.

Respecto a la cuestión de género, si bien hay que señalar que quizás no todas las teorías o disciplina científicas incorporan necesariamente el sesgo de género (Pérez Sedeño, 2001), para nuestro caso es relevante poder reconstruir si hubo mujeres en los comienzos y en el desarrollo de la microbiología, si es una disciplina dominada por los varones, y si existe espacios y temporalidades desigualmente distribuidos entre varones y mujeres. 
Una historia situada de la microbiología daría lugar a historias locales en la que aparecen en su interdependencia espacios, relaciones sociales, relaciones de dominación,instituciones, individuos y colectivos de individuos, procesos temporales, conceptos, teorías y prácticas científicas que interactúan entre sí en un contexto sociocultural, natural e híbrido definido. Estas historias locales, a su vez, construyen y son construidas por la historia global en un espacio de relaciones por donde viajan, circulan, se intercambian y se localizan teorías, prácticas de enseñanzas, equipos, bibliotecas, profesores, etc (Raj, 2006; Vessuri, 2007; Podgorny 2007). La tensión entre las historias locales y la historia global abre una agenda de investigación sobre los espacios y tiempos de los contenidos, las condiciones y modalidades de los intercambios (desiguales), como también de las apropiaciones, resistencias y recirculación de lo intercambiado.

Si se reconoce el carácter central de una geopolítica de la investigación microbiológica, una visión más compleja de la dinámica actual de la microbiología requeriría hacer visible, en la medida en que fuera así, si hay centros y periferias en esta y, en tal caso, cómo desde las periferias se construyen los centros (Bertomeu Sánchez \& Garcia Belmar, 2006), mostrando el carácter constitutivamente híbrido de estos (Chakrabarty, 1989). Hacer visible esto, quizás, sea el gran desafío para los futuros estudios sobre microbiología y la ciencia en general en la región. En términos de Said (1978), se trataría de una historia que busque desocultar los presupuestos de la microbiología central que se reconocen como propias, cuando en realidad fueron enunciadas en la periferia.

A modo de cierre, armados con este enfoque, se puede establecer marcos descriptivos comunes y procedimientos de creación de modelos para observar todo tipo de flujos en el espacio-tiempo. Entre ellos podemos nombrar: la conformación de disciplinas y profesiones microbiológicas, la circulación de los conocimientos microbiológicos, las modalidades de ingreso y desarrollo en cada país latinoamericano, la constitución de identidades propias, las agendas de investigación y su articulación con los problemas sociales, los conceptos, temas, teorías y metodologías, las redes de comunicación y relaciones sociales, el carácter sexuado y los marginados y marginadas, las enfermedades, los agentes microbianos, las especialidades, los nodos de poder cognitivos/políticos centralizados, las condiciones geográficas y poblacionales, las políticas científicas, de salud, educación y económicas, las agencias y organismos internacionales, los desarrollos institucionales (académicos, estatales y privados), la formación de los microbiólogos y microbiólogas, las revistas y congresos, las redes entre países, etc. Todos estos elementos, que poseen una estructura y ordenamiento espacial, temporal y en muchos casos de género, son claves para tener una comprensión ajustada de la microbiología y su historia en AL. Cada una de estas dimensiones da lugar a historias que ponen en visibilidad diferentes aspectos, todos parciales, todos importantes, todos situados. 


\section{NOTAS}

1 Quisiera agradecer la atenta lectura de un primer borrador realizada por Ronny Viales Hurtado (Universidad de Costa Rica) y Oscar Vallejos (Universidad Nacional del Litoral). Sus comentarios críticos han enriquecido el trabajo.

2 Como señala Vessuri, "La ciencia occidental dio lugar a un conjunto muy poderoso de dispositivos sociales para validar el conocimiento y, de hecho, para mover el conocimiento de unos sitios a otros" (Vessuri, 1996, p. 201)

3 Tributario esta perspectiva es el denominado "giro geográfico" en el estudio de la ciencia. De interés son los trabajos de Dorn (1991) y de Livingstone (1995, 2003), que indagan en las nociones de "sitio", "región", "circulación" y de Salvatore (2007) en donde se problematizan los "lugares" del saber. También el trabajo de Secord (2004) que entiende la ciencia como una forma de acción comunicativa ("communicative action").

4 Con ello se buscaba disolver la distinción tradicional entre los contextos de justificación y del descubrimiento.

5 Aquí suponemos que AL, más allá de su heterogeneidad, es una región en tanto que se estructura como un todo en términos materiales (cualidades físicas del terreno, régimen climatológico, entornos construidos y límites tangibles), como también en términos simbólicos (ideas, recuerdos, historia, comunidad imaginada y similares).

6 El tiempo de las mujeres, en tanto colectivo feminista que lucha por el cambio de las condiciones de su existencia societal, y en la ciencia en particular, sin duda no es el mismo tiempo que tiene los varones. En efecto, a las mujeres les urge cambiar el mundo social y científico, mientras que los varones tienen todo el tiempo del mundo tanto para proponer el cambio como para sostener dichos mundos. Esto se debe a las condiciones de privilegio que poseen.

7 Expresamente afirma que busca "unir lo muy contemporáneo con el tiempo largo de nuestras sociedades, la esfera de las actividades científicas, las de lo social y de los valores" (Pestre, 2005, p. 18).

"El concepto de proyecto cognitivo busca comprender la dinámica de la investigación como el armado y despliegue de proyectos cognitivos que son una respuesta compleja del agente a las condiciones, los recursos y las limitaciones que dan forma a su vida cotidiana y a su actividad de investigación. De modo que son unidades que ensamblan lo social y lo epistémico de manera tal que no se pueden desbrozar y esto es lo que los hace unidades de análisis relevantes para entender socialmente la producción, el mantenimiento y el cambio del conocimiento" (Vallejos, 2012).

Según Hebe Vessuri, su estudio permite hacer visible cómo se ponen en juego relaciones de poder, se determinan los métodos de trabajos, se constituyen las agendas de investigación y se establecen las formas de transferencia y difusión (Díaz, Texera \& Vesuri, 1983). Además, visibilizan cómo piensan las instituciones, expresión concreta de las estructuras mentales o de las representaciones de una determinada sociedad que intervienen y dan forma a la ciencia.

10 Esta posición lo acerca a las doctrinas neoliberales e individualistas de la década de 1980. En efecto, mientras que una de sus máximas representantes políticas Margaret Tatcher afirmó que "la sociedad no existe. Sólo existen los individuos, hombres y mujeres, y las familias". 
Latour, por su parte, sostuvo "la noción de sociedad es el último vestigio de trascendencia en las ciencias sociales que no son afectadas por la religión (...). No cumple ninguna función, pero tranquiliza, reconforta moralmente y permite que le sociólogo tenga un panorama. Precisamente por ello la combato" (Outhwaite, 2008, p. 146).

11 Como lo expresa Buch "Si bien el tipo de reglas, normas y valores que organizan la acción de un investigador hacia el "interior" de la Ciencia y el "interior de la nación son diferentes, ambas "interioridades" responden a una misma forma de pensar que establece "límites" y formas de regulación social que definen de modo distinto qué tipo de entidades o sujetos hay, qué hay que hacer en cada caso, con quién y cómo hay que hablar cuando se trata del "afuera" y del "adentro". En el caso de la nación, adentro hay "nativos" y afuera "extranjeros". En el caso de la Ciencia, hacia adentro de sus fronteras hay "pares" y hacia afuera hay "legos". En este sentido no existe mayores dificultades para entender el problema del nacionalismo y el internacionalismo en la ciencia: es la tensión en la definición de un otro a la nación o un otro a la ciencia. O si se prefiere, definir la identidad última que establece el espacio de solidaridad fundamental de un investigador como científico o como miembro de una comunidad nacional" (Buch, 2006, pp. 421-422).

12 Según Vessuri, los usos del concepto de periferia que se han realizado hasta el momento tienen más bien un carácter descriptivo para ubicar diferentes grupos, instituciones o la ciencia de un país en un mismo sistema intelectual, universitario o científico. Esta situación abre una cuestión específica: “¿Cómo hacer pasar el término periférico del nivel existencial al nivel teórico?" (Vessuri 1993, p. 727). Para un estudio de los significados y forma de abordar esta problemática, véase Matharan, 2016.

13 Esto no implicó, por supuesto, que los conocimientos producidos superasen las jerarquías impuestas por el sistema académico mundial, ni alcanzara altos niveles de circulación internacional o de exportación hacia los centros (Beigel, 2010).

14 "La geohistoria es el estudio de un doble vínculo, de la naturaleza con el hombre y del hombre con la naturaleza, el estudio de una acción y de una reacción, mezcladas, confundidas, incesantemente reanudas, en la realidad de cada día" (Braudel, 2002b, p. 78).

15 Con ello, el concepto de co-producción desmantela una narrativa dominante del poder que supone una separación tajante entre naturaleza y sociedad y el lugar de los expertos a la hora de definir y proponer soluciones a problemas sociales y naturales (Jasanoff, 2011).

16 Pero el uso del concepto de género abarca mucho más: hay marcas genéricas que van más allá de la distinción entre varones y mujeres.

17 Faltan trabajos que aborden, por ejemplo, la emergencia, proliferación y redefinición de la identidad de la microbiología en ramas como la parasitología, micología, virología, microbiología en alimentos, industrial o ambiental, entre otras.

18 Aquí es necesario distinguir la microbiología como profesión de la profesión del investigador en microbiología. A un lado, tenemos la delimitación de una profesión que monopoliza el acceso a los títulos y a los empleos correspondientes; por el otro, la construcción de un campo científico, con sus asociaciones, sus reuniones, sus revistas, sus medallas y sus representaciones oficiales. 


\section{REFERENCIAS}

Anderson, B. (1993). Comunidades imaginadas. Reflexiones sobre el origen y la difusión del nacionalismo. México: FCE

Beigel, F. (directora). (2010). Autonomía y dependencia académica. Universidad e investigación científica en un circuito periférico: Chile y argentina (1950-1980). Buenos Aires: Editorial Biblos.

Bensaude-Vincent, B. y Stengers. I. (1997). Historia de la Química. Madrid: Addison- Wesley

Braudel, F. (2002). Antes del Mediterráneo. En Braudel, F. (Ed), Las ambiciones de la historia (pp. 265-291). Barcelona: Crítica.

Braudel, F. (2002a). La larga duración. En Braudel, F. (Ed), Las ambiciones de la historia (pp. 127-146). Barcelona: Crítica.

Braudel, F. (2002b). Geohistoria: la sociedad, el espacio y el tiempo. En Braudel, F. (Ed), Las ambiciones de la historia (pp. 53-87). Barcelona: Crítica.

Bertomeu Sánchez, J. y Garcia Belmar, A. (2006). La Revolución Química. Entre la historia y la memoria. Valencia: Universitat de València.

Burke, P. (2003). Formas de hacer historia. Madrid: Alianza Editorial

Buch, A. (2006). Forma y función de un sujeto moderno. Beranrdo Houssay y la fisiología argentina (1900-1943). Bernal: Universidad Nacional de Quilmes.

Chakrabarty, D. (1989). Rethinking Working-Class History. Bengala 1890-1940. Princeton y Oxford: Princeton University Press.

Cueto, M. (1996). La excelencia en las ciencias biomédicas del siglo XX. En Saldaña, J.J (Ed.), Historia social de las ciencias en América Latina (pp. 482-492). México: UNAM Porrúa.

Chartier, R. (2007). La historia o la lectura del tiempo. Barcelona: Gedisa.

Chartier, R. (1996). Escribir las prácticas. Foucault, de Certeau, Marín. Buenos Aires: Mantantial

Dagnino, R. y Thomas, H. (2000). Elementos para una renovación explicativa-normativa de las políticas de innovación latinoamericanas. Espacios, 21(2), 5-30.

Díaz, E., Texera, Y. y Vessuri, H. (1983). La ciencia periférica. Carácas: Monte Ávila Editores

Dorn, H. (1991). The geography of Science. Baltimore: The Johns Hopkins University Press.

Fox Keller, E. (1991). Reflexiones sobre género y ciencia. Valencia: Alfons el Magnànim.

García, S. (2006). Ni solas ni resignadas: la participación femenina en las actividades científicoacadémicas de la Argentina en los inicios del siglo XX. Cadernos Pagu, 27, 133-172. 
Gavroglu, K., Patiniotis, M., Papanelipoulou, F., Simoes, A., Carneiro, A., Diogo, M., P. Carneiro, M. P., Bertomeu Sánchez, J. R., García Belmar, R. y Nieto Galán, A. (2008). Science and Technology in the European Periphery: Some Historiographical Reflections. History of Science, 46, 153-175.

Haraway, D. (1988). Situated Knowledges. Feminist Studies, 14, 575-599.

Harvey, D. (2007). Espacios del capital. Hacia una geografía crítica. Madrid: Akal.

Hufbauer, K. (1982). The Formation of the German Chemical Community (1720-179). Berkeley: University of California Press.

Jasanoff, S. (2013). Ensamblando el aire: una coproducción de materia y materia discutible. En Restrepo Forero, O. (Ed.), Ensamblando estados. Proyecto ensamblado en Colombia (pp. 465475). Bogotá: Universidad Nacional de Colombia.

Jasanoff, S. (2011). Momentos constitucionales en el gobierno de la ciencia y la tecnología. En Pérez Bustos, T. y Lozano-Borda, M. (Eds.), Ciencia, tecnología y democracia: reflexionas en torno a la apropiación social del conocimiento (pp. 17-32). Medellín: Universidad EAFIT.

Jasanoff, S. (2004). Status of Knowledge; the co-production of science and social order. London: Routledge.

Koselleck, R. (2001). Estratos del tiempo. En Koselleck, R. (Ed), Los estratos del tiempo: estudios sobre la historia (pp. 35-42). Barcelona: Paidós.

Koselleck, R. (2001a). Los estratos del tiempo: estudios sobre la historia. En Koselleck,

R. (Ed.), Espacio e historia (pp. 93-111). Barcelona, Paidós

Kreimer, P. (2010). Nacimiento, muerte y resurrección de la biología molecular en la Argentina. Aspectos sociales, políticos y cognitivos. Editorial Eudeba: Buenos Aires.

Latour, B. (1995). Dadme un laboratorio y moveré el mundo. En Iranzo, J. M., Blanco, J. R., Gonzalez de la Fe, T., Torres, C., Cotillo, A. (Eds.), Sociología de la ciencia y la tecnología (pp.237-257). Madrid: Consejo Superior de Investigaciones Científicas.

Ledesma-Mateos, I. (2009). Biología, institución y profesión: centros y periferias. México: Ediciones de Educación y Cultura.

Le Goff, J. (1997). Pensar la historia. Modernidad, presente, progreso. Barcelona: Paidos.

Livingstone, D.N. (2003). Putting Science in Its Place. London: University of Chicago Press.

Livingstone, D.N. (1995). The spaces of knowledge: Contributions towards a historical geography of science. Environment and Planning D: Society and Space, 13, 5-34.

Matharan, G. (2016). La dinámica centro-periferia en el estudio de la ciencia en América Latina: notas para una reflexión historiográfica sobre la Argentina. El hilo de la Fábula, 16(14), 33-48. 
Matharan, G. (2011). Estado, Universidad e Industria: el surgimiento y la dinámica de investigación en catálisis heterogénea en Argentina (1942-1983) (Tesis de Maestría). Bernal: Universidad Nacional de Quilmes.

Nowotny, H. (2011). ¿Salirse de la ciencia es salir de la sincronia? Informe sobre las ciencias sociales en el mundo: las brechas del conocimiento (319-322). México: UNESCO-Foro Consultivo Científico y Tecnológico, AC.

Outhwaite, W. (2008). El futuro de la sociedad. Buenos Aires: Amorrortu.

Pérez Sedeño, E. (2001). La deseabilidad epistémico de la equidad en ciencia. En Frías

Ruiz, V. (Ed), Las mujeres ante la ciencia del siglo XXI (pp.17-37). Madrid: Editorial Comlutense.

Pestre, D. (2005). Ciencia, Dinero y política. Buenos Aires: Ediciones Nueva Visión.

Podgorny, I. (2007). De angeles, gigantes y megaterios. El intercambio de fosiles de las provincias del Plata en la primera mitad del siglo XIX. En Salvatore, R. (Comp.), Los lugares del saber. Contextos locales y redes transnacionales en la formación del conocimiento moderno (pp. 125152). Rosario: Beatriz Viterbo Editora.

Prego, C. (1996). Formación y desarrollo de una tradición científica: el campo bio-médico en la Argentina. En Albornoz, M., Kreimer, P. y Glavich, E. (Eds.), Ciencia y Sociedad en América Latina (pp.487-501). Bernal: Universidad Nacional de Quilmes.

Raj, K. (2006). Relocating Modern Science: Circulation and the Construction of Scientific Knowledge in South Asia and Europe: Seventeenth to Nineteenth Centuries. Delhi: Permanent Black.

Revel, J. (2005). Microanálisis y construcción de lo social. En Revel, J. (Ed.), Un momento historiográfico. Trece ensayos de historia social (pp. 45-62). Buenos Aires Manantial.

Said, E. (1978). L'orientalisme. L'Orient créé par L'Occident. Paris: Seuil.

Sánchez Ron, J, M. (1992). El poder de la ciencia. Historia Socio-Económica de la física (siglo XX). Madrid: Alianza Editorial.

Secord, J. (2004). Knowledge in Transit. Isis, 95, 654-672.

Saldaña, J. J. (1996). Introducción. Teatro científico americano. Geografía y cultura en la historiografía latinoamericana de la ciencia. En Saldaña, J. J. (Coord.), Historia social de las ciencias en América Latina (pp. 7-41). México: Miguel Ángel Porrúa.

Salvatore, R. (2007). Los lugares del saber. Contextos locales y redes transnacionales en la formación del conocimiento moderno. Rosario: Beatriz Viterbo Editora.

Shapin, S. (2010). Never pure. Historical studies of science as if it was produced by people with bodies, situated en time, space, culture, and society, and struggling for credibility and authority. Baltimore: The Johns Hopkins University Press. 
Shapin, S. (1998). Placing the View from Nowhere: Historical and Sociological Problems in the Location of Science. Transactions of the Institute of British Geographers, 23(1), 5-12.

Shapin, S. (2000).. La revolución científica. Una interpretación alternativa. Barcelona: Paidós

Shinn, T. (1999). Prólogo. En Kreimer, P. (Ed.), De probetas, computadoras y ratones. La construcción de una mirada sociológica de la ciencia (pp. 13-24). Bernal: Universidad Nacional de Quilmes.

Scott, J. (2003). Historia de las mujeres. En Burke, P. (Ed.), Formas de hacer historia (pp. 59-89). Madrid: Alianza Editorial.

Vallejos, O. (2010). Universidad-empresa: un estudio histórico-político de la conformación del CETRI Litoral. Revista CTS, 6(16), 123-152.

Vallejos, O. (2012). Proyectos cognitivos: una categoría para estudiar dinámicas de investigación científica. Ponencia presentada en la IX Jornadas Latinoamericanas de Estudios Sociales de la Ciencia y la Tecnología, México

Viales, R. (2018). América Central y su(s) intercontexto(s). Entre la Historia mundial, la Historial global y el giro espacial. En Díaz Arias, D. y Viales, R. (Eds.), Historia Global y circulación de saberes en Iberoamérica, siglos XVI-XXI (pp. 47-74). San José: Universidad de Costa Rica.

Vessuri, H. (1996). El proceso de institucionalización. En Salomón, J.J., Sagasti, F. y Sachs, C. (Comps.), Una búsqueda Incierta. Ciencia, Tecnología y Desarrollo (pp. 199-233). México: Fondo Cultura Económica.

Vessuri, H. (1995). El crecimiento de una comunidad científica en la Argentina. Cad. His.Fil. Ci, Campinas, 5, Número Especial, 173-222.

Vessuri, H. (1991). Universalismo y nacionalismo en la ciencia moderna. Una aproximación desde el caso venezolano. Quipu, 8(2), 255-271.

Vessuri, H. (1984). Ciencia Académica en la Venezuela Moderna. Caracas: Fondo Editorial.

Vessuri, H. (1993). Intercambios internacionales y estilos nacionales periféricos: aspectos de la mundialización de la ciencia. En Lafuente, A., Elena, A. y Ortega, M. L. (Eds.), Mundialización de la ciencia y cultura nacional (pp. 725-733). Madrid: Doce Calles.

Vessuri, H. (2007). La movilidad científica desde la perspectiva de América Latina. En Vessuri, H (Ed.), "O inventamos o erramos". La ciencia como idea-fuerza en América Latina (pp.307325). Bernal: Universidad Nacional de Quilmes. 